\title{
Hemşirelik öğrencilerinin benlik saygısı ve boyun eğici davranışlarının incelenmesi
}

\section{The relation between submissive behaviors and self esteem state of nursing students}

\author{
Serap Torun*, Sevban Arslan, Evşen Nazik, Meltem Akbaş, Sibel Öner Yalçın \\ Hemşirelik Bölümü (Dr. S. Torun, Yrd. Doç. Dr. S. Arslan, Yrd. Doç. Dr. E. Nazik, Dr. M. Akbaş, \\ Öğr. Gör. S. Ö. Yalçın), Çukurova Üniversitesi Adana Sağlık Yüksekokulu, TR-01330 Adana
}

\begin{abstract}
Özet
Amaç. Bu çalışma hemşirelik öğrencilerinin benlik saygılarını ve boyun eğici davranışlarını incelemek ve etkileyen bazı sosyo-demografik faktörleri belirlemek amacıyla yapılmıştır. Yöntem. Tanımlayıcı olarak yapılan araştırma 236 hemşirelik öğrencisi ile Kasım-Aralık 2010 tarihleri arasında yapılmıştır. Veriler öğrencilerin sosyodemografik özelliklerini içeren soru formu, Coopersmith Benlik Saygısı Ölçeği (CBSÖ) ve Boyun Eğici Davranışlar Ölçeği (BEDÖ) kullanılarak toplanmıştır. Elde edilen veriler SPSS programında analiz edildi. Bulgular. Öğrencilerin BEDÖ ortalamaları $37,14 \pm 9,26$ ve BSÖ ortalamaları $68,56 \pm 18,27$ olarak bulunmuştur. Öğrencilerin benlik saygısı düzeyinin bulundukları sınıf ile anlamlı farklılık gösterdiği saptanmıştır $(\mathrm{P}=0,005)$. Öğrencilerin boyun eğici davranışları ile sosyodemografik faktörleri arasında anlamlı farklılık saptanmamıştır. Yapılan korelasyon analizi ile boyun eğici davranışlar ve benlik saygısı arasında istatistiksel olarak anlamlı bir ilişki olduğu saptanmıştır $(r=-$ $0,426, \mathrm{p}<0,01)$. Sonuç. Bulgular boyun eğici davranışlar ve benlik saygısı arasında negatif bir korelasyon olduğunu göstermektedir.
\end{abstract}

Anahtar sözcükler: Hemşirelik öğrencisi, benlik saygısı, boyun eğici davranış

\begin{abstract}
Aim. The aim of this study is to determine relationship between submissive behaviors and self esteem of nursing students and to determine the influence of some socio-demographic factors. Method. This descriptive research has been performed with 236 nursing students between November - December 2010. Research data was derived from a questionnaire that included threepartsnamely the sociodemographic Questionnaire, Coopersmith Self- Esteem State (CCES) and Submissive Acts Scale (SAS). The data were analyzed by using the SPSS program. Results. Average SAS and CSES levels of the participants were $37.14 \pm 9.26$ and $68.56 \pm 18.27$ respectively. CSES levels of the students were found to be significantly different among classes $(\mathrm{P}=0,005)$ There was no relation between sociodemographic factors and SAS. A significant relationship was found between submissive behaviors and self esteem by the correlation analysis $(r=-0.426$, $\mathrm{p}<0.01)$. Conclusion. Our results show that there is a negative correlation between submissive behaviors and self esteem.
\end{abstract}

Keywords: Nursing students, self esteem, submissive act

Geliş tarihi/Received: 26 Aralık 2011; Kabul tarihi/Accepted: 11 Eylül 2012

\section{*Iletişim adresi:}

Dr. Serap Torun, Hemşirelik Bölümü, Çukurova Üniversitesi Adana Sağlık Yüksekokulu, TR01330 Adana. E-posta: torunserap@gmail.com

\section{Giriş}

Benlik kavramı (self-concept), kişinin kendisine ilişkin algılarını, duygularını ve tutumlarını içermektedir $[1,2]$. Benlik imgesinin beğenilip benimsenmesi benlik saygısını 
oluşturmaktadır. Benlik saygısı kendinden memnun olma durumu olup kendini sevmeye ve sevilmeye değer bulmayla birlikte, kendini olduğu gibi kabullenerek kendine güvenmeyi sağlayan olumlu bir ruh halidir [1]. Benlik saygısı kavramı, kişinin kendisini sürekli olarak değerlendirmesidir ve yaşam boyu devam eden bir süreçtir [3]. Benlik saygısının şekillenmesinde ailedeki birey sayısı, sosyoekonomik ve kültürel düzey, cinsiyet, fiziksel sağlık, görünüm ve kişilerarası ilişkiler önemli yer tutmaktadır [1]. Aile içi ilişkilerle başlayan etkilenme süreci sosyalleşmeyle birlikte hız kazanmaktadır. Ebeveynlerin yaklaşımları ve beklentileri okul yaşantısına da yansımakta, arkadaş ve eğitimci tutumu benlik saygısını etkilemektedir [4]. Eğitim süreci içinde hemşirelik öğrencilerinin eğiticileri, arkadaşları, hastaları ve diğer meslek üyeleriyle yaşayacakları iyi ya da kötü deneyimler benlik saygısı üzerinde olumlu veya olumsuz etkilere yol açabilmektedir [5]. Bununla birlikte eğitim hayatında zorunlu olarak rol değişimleri yaşamaktadırlar ve bu değişimler kendilerini algılamaları üzerinde etkiler yaratmaktadır. Benlik saygısı etkilendiği takdirde öğrencide itaatkâr bir tutum gelişmektedir. Bu nedenle boyun eğici davranışların temelinde yatan önemli bir etken ise düşük benlik saygısıdır denilebilir. Boyun eğici davranış; başkalarını kırmamaya, incitmemeye özen gösteren, herkesi memnun etmeye çalışan, iyiliksever olma eğilimli olan, aşırı verici, "hayır" diyemeyen, "evet" demeye eğilimli, hoşlanmadığı durumları ifade etmekte zorlanan, öfkelerini göstermekte zorluk çeken, sürekli onaylanma gereksinimi duyan, düşüncelerini ve haklarını savunamayan vb. davranışlarla gözlenebilen bir kişilik özellikleri kümesidir [6]. Profesyonel bir hemşirenin bilgili, araştıran, okuyan, sorgulayan, planlayan, karar veren ve uygulayan kişi olması beklenmektedir. Ek olarak lisans mezunu hemşirelerden liderlik özelliklerine sahip, kendini ifade edebilen, eğitim yapabilen, etkili iletişim kurabilen, etkin problem çözebilen, çabuk karar verip hareket edebilen ve kararlarının sorumluluğunu üstlenen, yeterli ve yetkili hemşireler olmaları beklenmektedir $[7,8]$. Bu nedenle hemşirelik öğrencilerinin hastayla güçlü ve terapötik ilişkiler kurmak için mezuniyet öncesi olumlu benlik imajı ve mesleki kimliğe sahip olması gerekmektedir [9]. Bu bağlamda eğitim süresince öğrencinin özgüveninin yüksek olması istendik bir durum olarak kabul görmektedir. Profesyonel hemşire adaylarının çağdaş ve istendik özelliklere sahip olabilmeleri, mesleki başarı elde etmeleri ve bunun yanında bireysel doyum sağlamaları için; girişken, sağlıklı ilişkiler kurabilen, kendilerini kabul eden ve aynı zamanda çevreden kabul gören, özgüveni ve özsaygı düzeyleri yüksek bireyler olarak yetişmeleri kuşkusuz çok önemlidir. Dolayısıyla bireyin aile ve sosyal çevresi ile eğitim sürecindeki yaşantılar tüm bunları etkilemektedir.

Bu çalışma bir Sağlık Yüksekokulu'nda öğrenim gören hemşirelik öğrencilerinin benlik saygılarını ve boyun eğici davranışlarını incelemek ve etkileyen bazı sosyo-demografik faktörleri belirlemek amacıyla yapılmıştır.

\section{Gereç ve yöntem}

Tanımlayıcı olarak yapılan çalışmada araştırmanın evrenini bir Sağlık Yüksekokulu'nda bulunan $450 \mathrm{Hemşirelik} \mathrm{bölümü} \mathrm{öğrencileri,} \mathrm{örneklemini} \mathrm{ise} \mathrm{araştırmaya} \mathrm{katılmayı} \mathrm{kabul}$ eden 236 öğrenci oluşturmuştur. Araştırma okul idaresinden gerekli izinler alınarak 2010 yılının Kasım-Aralık ayları arasında yapılmıştır. Araştırmaya katılanların sözlü olurları alınmıştır. Araştırmada kullanılan veri toplama formu 3 bölümden oluşmuştur. Birinci bölüm öğrencilerin yaş, cinsiyet, sınıf, yaşanılan yer, aile yapısı, kardeş sayısı gibi sosyodemografik özellikleri içeren sorulardan oluşmuştur. İkinci bölümde 1986'da Stanley Coopersmith tarafından geliştirilmiş olan, Turan ve Tufan [10] tarafından Türkçe'ye uyarlanarak geçerlik ve güvenirlik çalışması yapılan Coopersmith Benlik Saygısı Ölçeği (BSÖ) kullanılmıştır. Turan ve Tufan [10] birer yıl arayla yapmış oldukları çalışmalarda ölçeğin test-tekrar test güvenirliğini 0,65 ve 0,76 olarak saptamışlardır. Ölçek, "benim gibi" ya da "benim gibi değil" biçiminde işaretlenebilen 25 maddeden oluşmaktadır. Bu maddelerde kişinin hayata bakış açısı, aile ilişkileri, sosyal ilişkileri ve dayanma gücü ile ilgili ifadeler bulunmaktadır. Alınan puanlar 0 ile 100 arasında değişmektedir. Alınan puanın ortalamanın altında olması benlik saygısının düşüklüğüne, ortalamanın üzerinde 
olması benlik saygısının yüksekliğine işaret etmektedir. Ölçeğin bu çalışma için Cronbach Alfa iç tutarlılık katsayısı 79 olarak belirlenmiştir.

Üçüncü bölümde Boyun Eğici Davranışlar Ölçeği (BEDÖ) kullanılmıştır. Gilbert ve Allan [11] tarafindan geliştirilen Submis-sive Acts Scale, Savaşır ve Şahin [12] tarafından Türkçe'ye uyarlanmış, geçerlik ve güvenirlik çalışmaları yapılmış ve BEDÖ olarak adlandırılmıştır. BEDÖ 16 maddeden oluşmaktadır. Her maddede sözü edilen davranışın kişiyi ne kadar iyi tanımladığı sorulmuş ve değerlendirme "hiç tanımlamıyor", "biraz tanımlıyor", "oldukça tanımlıyor", "iyi tanımlıyor" ve "çok iyi tanımlıyor" şeklinde beş eşit aralığa bölünerek yapılmıştır. Ölçekten alınan puanların yüksekliği, daha fazla boyun eğici davranışa işaret etmektedir. Ölçeğin .89 olan Cronbach Alfa iç tutarlılık katsayısı, bu çalışma için .80 olarak belirlenmiştir.

Elde edilen verilerin istatistiksel analizleri SPSS for Windows 15.0 programı ile yapılmıştır. Verilerin değerlendirilmesinde tanımlayıcı istatistikler, t testi, Kruskal Wallis, korelasyon analizleri yapılmıştır. Anlamlılık değeri olarak $\mathrm{p}<0.05$ alınmıştır.

\section{Bulgular}

Araştırma kapsamına alınan öğrencilerin: yaş ortalamalarının $20.00 \pm 1,39$ virgülden sonra üç sıra ikiye indirilmeli (min: 17, max: 25) olduğu, \%30,1'inin birinci sınıf, \%9,3'ünün dördüncü sınıf olduğu, \%75'inin kız öğrenci olduğu saptanmıştır. Öğrencilerin $\% 82,2$ 'sinin çekirdek ailede yaşadığı, \%57,2'sinin 1-3 kardeş olduğu, \%72,4'ünün kentte yaşadığı belirlenmiştir (Tablo 1).

Tablo 1. Öğrencilerin tanımlayıcı özelliklerine göre BSÖ ve BEDÖ puan ortalamalarının dağılımı.

\begin{tabular}{|c|c|c|c|c|}
\hline $\begin{array}{l}\text { Sosyo-demografik } \\
\text { özellikler }\end{array}$ & $\begin{array}{l}\text { Sayı } \\
(n=236)\end{array}$ & $\begin{array}{l}\text { Yüzde } \\
(\%)\end{array}$ & BSÖ & BEDÖ \\
\hline \multicolumn{5}{|l|}{ Cinsiyet } \\
\hline $\mathrm{K} 1 \mathrm{z}$ & 177 & 75,0 & $69,55 \pm 18,18$ & $36,81 \pm 9,27$ \\
\hline Erkek & 59 & 25,0 & $65,55 \pm 18,36$ & $38,10 \pm 9,23$ \\
\hline Test değeri & & & $\mathrm{t}=1,460 \mathrm{P}=0,146$ & $\mathrm{t}=-0,925 \mathrm{P}=0,356$ \\
\hline \multicolumn{5}{|l|}{ Sinıf } \\
\hline 1 & 71 & 30,1 & $72,84 \pm 17,87$ & $38,76 \pm 9,76$ \\
\hline 2 & 69 & 29,2 & $66,49 \pm 19,24$ & $36,17 \pm 8,17$ \\
\hline 3 & 74 & 31,4 & $64,64 \pm 16,61$ & $37,80 \pm 9,28$ \\
\hline 4 & 22 & 9,3 & $74,36 \pm 18,62$ & $32,68 \pm 9,59$ \\
\hline Test değeri & & & $\mathrm{KW}=12,871 \mathrm{P}=0,005$ & $\mathrm{KW}=7,368 \mathrm{P}=0,061$ \\
\hline \multicolumn{5}{|l|}{ Yaşanılan yer } \\
\hline Köy & 37 & 15,7 & $64,43 \pm 18,96$ & $36,57 \pm 8,39$ \\
\hline Kasaba & 28 & 11,9 & $69,14 \pm 18,17$ & $36,18 \pm 8,72$ \\
\hline Kent & 171 & 72,4 & $69,35 \pm 18,12$ & $37.42 \pm 9,55$ \\
\hline Test değeri & & & $\mathrm{KW}=2,046 \mathrm{P}=0.360$ & $\mathrm{KW}=0,537 \mathrm{p}=0,764$ \\
\hline \multicolumn{5}{|l|}{ Aile yapısı } \\
\hline Çekirdek aile & 194 & 82,2 & $68,57 \pm 18,66$ & $37,48 \pm 9,33$ \\
\hline Geniș aile & 34 & 14,4 & $69,52 \pm 16,88$ & $35,12 \pm 8,98$ \\
\hline Parçalanmış aile & 8 & 3,4 & $64,00 \pm 15,26$ & $37,25 \pm 8,61$ \\
\hline Test değeri & & & $\mathrm{KW}=0,891 \mathrm{P}=0,640$ & $\mathrm{KW}=2,278 \mathrm{P}=0,320$ \\
\hline \multicolumn{5}{|l|}{ Kardes sayısı } \\
\hline 1-3 kardes & 135 & 57,2 & $71,28 \pm 16,76$ & $37,24 \pm 8,90$ \\
\hline 4-6 kardeş & 74 & 31,4 & $66,16 \pm 19,98$ & $37,12 \pm 9,84$ \\
\hline 7-+ kardeş & 27 & 11,4 & $61,48 \pm 18,46$ & $36,67 \pm 9,73$ \\
\hline Test değeri & & & $\mathrm{KW}=7,377 \mathrm{P}=0,025$ & $\mathrm{KW}=0,217 \mathrm{P}=0,897$ \\
\hline
\end{tabular}

Kız öğrencilerin BSÖ puan ortalamasının $69,55 \pm 18,18$, BEDÖ puan ortalamasının $36,81 \pm 9,27$ olduğu; erkek öğrencilerin BSÖ puan ortalamasının $65,55 \pm 18,36$ olduğu, BEDÖ puan ortalamasının $38,10 \pm 9,23$ olduğu bulunmuştur. Öğrencilerin cinsiyeti ile BSÖ ve BEDÖ puan ortalamaları arasında istatistiksel olarak anlamlı bir ilişki 
bulunamamıştır $(\mathrm{p}>0,05)$. Birinci sınıfta öğrenim gören öğrencilerin BSÖ puan ortalamasının $72,84 \pm 17,87$, BEDÖ puan ortalamasının $38,76 \pm 9,76$ olduğu; dördüncü sınıf öğrencilerinin BSÖ puan ortalamasının 74,36 $\pm 18,62$ olduğu, BEDÖ puan ortalamasının 32,68 $\pm 9,59$ olduğu bulunmuştur. Öğrencilerin bulundukları sınıf ile BSÖ puan ortalamaları arasında istatistiksel olarak anlamlı bir ilişki saptanırken $(\mathrm{p}<0,05)$, BEDÖ puan ortalaması arasında anlamlı bir ilişki saptanmamıştır $(\mathrm{p}>0,05)$. 1-3 kardeş olan öğrencilerin BSÖ puan ortalamasının $71,28 \pm 16,76$ olduğu, BEDÖ puan ortalamasının 37,24 $\pm 8,90$ olduğu bulunmuştur. Öğrencilerin kardeş sayısı ile BSÖ puan ortalamaları arasında istatistiksel olarak anlamlı bir ilişki saptanırken $(\mathrm{p}<0,05)$, BEDÖ puan ortalaması arasında anlamlı bir ilişki saptanmamıştır ( $>0,05)$ (Tablo 1). Öğrencilerin BSÖ puan ortalamasının $68,56 \pm 18,27$, BEDÖ puan ortalamasının $37,14 \pm 9,26$ olduğu saptanmıştır (Tablo 2).

Tablo 2. Öğrencilerin BSÖ ve BEDÖ puan ortalamalarının dağılımı (n= 236).

\begin{tabular}{llll}
\hline Ölçek & Alt ve üst değerler & Iş̧aretlenen alt ve üst değerler & $\mathbf{X} \pm$ SD \\
\hline BSÖ toplam puanı & $0-100$ & $16-96$ & $68,56 \pm 18,27$ \\
BEDÖ toplam puanı & $0-64$ & $16-64$ & $37,14 \pm 9,26$ \\
\hline
\end{tabular}

Öğrencilerin BSÖ ve BEDÖ’ye ait puanları arasında negatif yönde anlamlı bir ilişki belirlenmiştir ( $\mathrm{r}=-0,426 \mathrm{p}<0,01)$ (Tablo 3). BSÖ puanları artarken BEDÖ puanlarının azaldığı saptanmıştır.

Tablo 3. Öğrencilerin BSÖ ve BEDÖ puan ortalamaları arasındaki ilişkinin incelenmesi.

\begin{tabular}{lll}
\hline Ölçekler & BSÖ & BEDÖ \\
\hline BSÖ & $r=1.000$ & $r=-0,426 p<0,01$ \\
BEDÖ & $r=-0,426 p<0,01$ & $r=1.000$ \\
\hline
\end{tabular}

\section{Tartışma}

$\mathrm{Bu}$ çalışma hemşirelik öğrencilerinin benlik saygılarını ve boyun eğici davranışlarını incelemek ve etkileyen bazı sosyo-demografik faktörleri belirlemek amacıyla yapılmıştır. Araştırma grubundaki öğrencilerin BSÖ puan ortalamasının $68,56 \pm 18,27$ olduğu saptanmıştır. Kahriman [2]'ın çalışmasında hemşirelik öğrencilerinin BSÖ puan ortalamasının 69,1 17,34 olarak belirlenmiştir. Ayrıca Özkan ve Özen [13]'in çalışmasında da BSÖ puan ortalaması 74,78 $\pm 16,2$ olarak saptanmıştır. Bizim çalışmamızda saptadığımız BSÖ ortalama puanı ile öğrencilerin benlik saygısının yüksek olduğunu söylemek olanaklıdır.

Araştırmada tüm sınıflarda BSÖ puan ortalamasının 50'nin üzerinde olduğu, son sınıf öğrencilerin BSÖ puan ortalamalarının en yüksek olduğu saptanmıştır. Ayrıca sınıflar arasındaki benlik saygısı puan ortalamaları arasındaki farkın anlamlı olduğu saptanmıştır $(\mathrm{p}=0.005)$. Dinçer ve Öztunç [14]'un, Karadağ ve ark. [15]'nın çalışmasında da tüm sınıflarda öğrencilerin BSÖ puan ortalamasının 50'nin üzerinde olduğu saptanmıştır. Ayrıca Karadağ ve ark. [15]'nın çalışmasında dördüncü sınıf öğrencilerinin BSÖ puan ortalaması en yüksek bulunmuştur. Sinıf ilerledikçe benlik saygısı puan ortalamasının artması, ilerleyen yaşa paralel olarak değişen bakış açısına, kendini algılamaya ve tanımaya, kendini gerçekleştirme yönünde hedef belirlemeye ayrıca üniversite eğitimini sürdürürken hem mesleki hem de sosyal alanda yaşanan deneyim ve bilgi artışından kaynaklanmış olabilir. Son sınıf öğrencilerinin alt sınıftaki öğrencilere göre mesleki açıdan daha bilgili ve deneyimli olmalarının benlik saygılarını arttırdığı düşünülebilir. Kardeş sayısı az olan öğrencilerin BSÖ puan ortalamalarının daha yüksek olduğu ve aradaki farkın anlamlı olduğu saptanmıştır. Karadağ ve ark. [15]'nın, Kahriman [2]'ın çalışmasında da benzer sonuçlar elde edilmiştir. Aile içinde kardeş sayısı azaldıkça ebeveynlerin çocuklarına ayırdıkları zamanın kalitesi artmakta, çocuk duygu, istek ve düşüncelerini daha rahat ifade etmekte, ebeveyn tarafindan birey olarak kabul görmekte 
bu da benlik saygısını arttırmaktadır. Araştırmada öğrencilerin BEDÖ puan ortalamasının $37,14 \pm 9,26$ olduğu ve öğrencilerin orta derecede boyun eğici davranışlar gösterdiği saptanmıştır. Yılmaz ve ark. [16]'nın çalışmasında hemşirelik öğrencilerinin BEDÖ puan

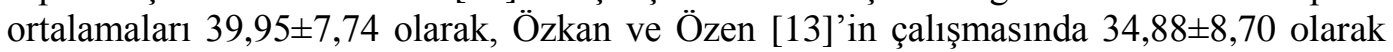
bulunmuştur. Kaya ve ark. [17]'nın çalışmasında tıp fakültesi öğrencilerinin BEDÖ puan

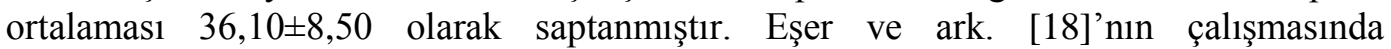

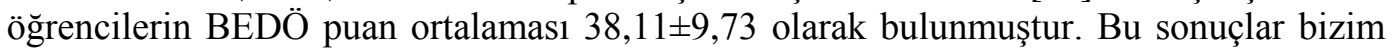
çalışma sonuçlarıyla benzerdir.

Çalışmada BEDÖ puan ortalamalarının birinci sınıf öğrencilerinde en yüksek, dördüncü sınıf öğrencilerinde ise en düşük olduğu saptanmıştır. Mete ve Çetinkaya [19]'nın çalışmasında da öğrencilerin BEDÖ puanları; birinci sınıfta en yüksek (birinci sınıf $\mathrm{X}^{-}=34,4$, ikinci sinıfta $\mathrm{X}^{-}=31,6$, üçüncü sinıfta $\left.\mathrm{X}^{-}=32,5\right)$ ve dördüncü sinıfta en düşük $\left(X^{-}=29,3\right)$ olduğu belirlenmiştir.

Çalışmada öğrencilerin bulundukları sınıflara göre BEDÖ puan ortalamaları arasında anlamlı bir fark olmadığı saptanmıştır. Benzer şekilde Eşer ve ark. [18] ile Koç ve ark.[6]'nın çalışmasında da sınıf ile BEDÖ puan ortalamaları arasında anlamlı bir fark olmadığı bulunmuştur. Bu sonuçlar sınıfın öğrencilerin boyun eğici davranışlar üzerinde etkili olmadığını düşündürmektedir.

Çalışmada çekirdek ailede yaşayan ve cinsiyeti erkek olan öğrencilerin BEDÖ puan ortalamasının daha yüksek olduğu bulunmuştur. Kaya ve ark. [17]'nın ve Koç ve ark. [6]'nın çalışmalarında da benzer sonuçlar tespit edilmiştir. Tekin ve Filiz'in [20] çalışmasında da erkek öğrencilerin boyun eğici davranış düzeylerine ilişkin ortalaması 35,39 iken kız öğrencilerin boyun eğici davranış düzeylerine ilişkin ortalaması 31,80'dir. $\mathrm{Bu}$ da bize erkek öğrencilerin boyun eğici davranış düzeyleri kız öğrencilerin boyun eğici davranış düzeylerinden yüksek olduğu sonucu ortaya çıkarmaktadır.

Araştırmada hemşirelik öğrencilerinin boyun eğici davranış durumu ve benlik saygısı düzeyi arasında istatistiksel olarak negatif yönde anlamlı bir ilişki tespit edilmiştir ( $\mathrm{r}=-$ $0,426 \mathrm{p}<0,01)$. Öğrencilerin BEDÖ puanı yükseldikçe benlik saygısı düşmektedir. Benzer şekilde Özkan ve Özen'in [13] çalışmasında da boyun eğici davranış durumu ve benlik saygısı düzeyi arasında negatif yönde ilişki saptanmıştır $(\mathrm{r}=-0,42, \mathrm{p}<0,01)$.

Araştırma sonucunda öğrencilerin benlik saygılarının iyi düzeyde olduğu, orta derecede ise boyun eğici davranışlar gösterdikleri belirlenmiştir. BSÖ ve BEDÖ’ye ait puanlar arasında negatif yönde anlamlı bir ilişki belirlenmiştir. Öğrencilerin benlik saygıları arttıkça boyun eğici davranışların azaldığı saptanmıştır. Araştırma sonuçları doğrultusunda öğrenme sürecinde bir motivasyon kaynağı olarak öğrencilerin benlik saygısını arttırmaya yönelen, insanın değerliliğini esas alan, öğrenci merkezli öğretim stratejilerinin uygulanması, bunun için okulların alt yapılarının incelenmesi, öğretim elemanlarının niteliklerinin arttırılması ile ilgili çalışmalarının yapılması önerilebilir. Ayrıca öğrencilerin boyun eğici davranışlarına yönelik kişisel-sosyal rehberlik kapsamında eğitici programlar düzenlenebilir ve öğretim elemanlarının öğrencilere karşı ortak anlayış ve tutum içerisinde olmalarına yönelik çalışmaları yapılabilir.

\section{Kaynaklar}

1. Yörükoğlu A. Gençlik Çağı: Gençlikte Benlik ve Kimlik. 11. Bask1, Özgür Yayınları, İstanbul 2000: 101-25.

2. Kahriman İ. Karadeniz Teknik Üniversitesi Trabzon Sağlık Yüksekokulu öğrencilerinin benlik saygıları ve atılganlık düzeylerinin bazı değişkenler açısından incelenmesi. Cumhuriyet Üniversitesi Hemşirelik Yüksekokulu Dergisi 2005; 9: 24-31.

3. Ünsar S, İşsever H. Trakya Üniversitesi Sağlık Hizmetleri Meslek Yüksekokulu öğrencilerinin benlik saygısını etkileyen faktörlerin incelenmesi. Hemşirelik Forumu 2003; 6: 7-11. 
4. Baymur F. Genel Psikoloji: Kişilik ve Benlik. 7. Baskı, İnkılap Kitabevi, İstanbul, 1985: 268-70.

5. du Toit D. A sociological analysis of the extent and influence of professional socialization on the development of a nursing identity among nursing students at two universities in Brisbane, Australia. J Advanced Nursing 1995; 21: 164-71.

6. Koç M, Bayraktar B, Çolak S. Üniversite Öğrencilerinde Boyun Eğici Davranışlarının Çeşitli Değişkenler Açısından İncelenmesi. Sosyal Bilimler Enstitüsü Dergisi 2010; 28: 257-80.

7. Özcan A. Hemşire-Hasta İlişkisi ve İletişim: Girişkenlik. 2. Baskı, Ankara, 2006: 229-56.

8. Yılmaz S, Ekinci M. Hemşirelik Yüksekokulu öğrencilerinde benlik saygısı ve atılganlık düzeyleri arasındaki ilişki. Atatürk Üniversitesi Hemşirelik Yüksekokulu Dergisi 2001; 2: 1-10.

9. Ohlen J, Segesten K. The professional identity of the nurse: concept analysis and development. J Advanced Nursing 1998; 28: 720-7.

10. Turan N, Tufan B. Coopersmith benlik saygısı envanteri'nin (SEI) geçerlikgüvenirlik çalışması. In: 23. Ulusal Psikiyatri ve Nörolojik Bilimler Kongresi; 1987; İstanbul-Türkiye, 816-7.

11. Gilbert, P, Allan S. Assertiveness, submissive behaviour and social comparison. British Journal of Clinical Psychology 1994; 33: 295-306.

12. Savaşır I, Şahin NH. Savaşır I, Şahin NH (eds): Boyun Eğici Davranışlar Ölçeği. Bilişsel-DavranışçıTerapilerde Değerlendirme: Sık Kullanılan Ölçekler. Ankara, Özyurt Matbaac1lik, 1997; s: 100-3.

13. Özkan İA, Özen A. The relation between submissive behaviours and self esteem state among nursing students. TAF Prev Med Bull 2008; 7: 53-8.

14. Dinçer F, Öztunç G. Hemşirelik ve Ebelik öğrencilerinin benlik saygısı ve atılganlık düzeyleri. Hacettepe Üniversitesi Sağlık Bilimleri Fakültesi Hemşirelik Dergisi 2009; 16: 22-33.

15. Karadağ G, Güner İ, Çuhadar D, Uçan Ö. Gaziantep Üniversitesi Sağlık Yüksekokulu hemşirelik öğrencilerinin benlik saygıları. Fırat Sağlık Hizmetleri Dergisi 2008; 3: 29-42.

16. Yılmaz S, Çeçen E, Yılmaz E, Yurttaş M, Bayır G, Akansel N, Yıldız H. Boyun eğici davranışlarda cinsiyete göre farklılık var mı?: Hemşirelik Bölümü örneği. Maltepe Üniversitesi Hemşirelik Bilim ve Sanatı Dergisi 2010 Sempozyum Özel Say1s1 342.

17. Kaya M, Güneş G, Kaya B, Pehlivan E.Tıp Fakültesi öğrencilerinde boyun eğici davranışlar ve şiddetle ilişkisi. Anadolu Psikiyatri Dergisi 2004; 5: 5-10.

18. Eşer İ, Khorshid L, Gürol Arslan G. Sağlık çalışanı olmaya aday öğrencilerin boyun eğici davranışlarının incelenmesi. İ.Ü. Florence Nightingale Hemşirelik Dergisi 2009; 17: 1-9.

19. Mete S, Çetinkaya E. Probleme dayalı öğrenim modelinin hemşire öğrencilerin boyun eğici davranışlarına etkisi. Zonguldak Sağlık Yüksekokulu Dergisi 2005; 1: 49-55.

20. Tekin M, Filiz K. Beden eğitimi ve spor yüksekokullarının antrenörlük eğitimive spor yöneticiliğibölümlerinde öğrenim gören öğrencilerin umutsuzluk ve boyun eğici davranış düzeylerinin çeşitli değişkenlere göre incelenmesi SPORMETRE. Beden Eğitimi ve Spor Bilimleri Dergisi 2008; VI: 27-37. 